\title{
Resenha
}

\section{Para além do realismo e do idealismo}

\section{ITAPARICA, André. Idealismo e Realismo na Filosofia de Nietzsche. São Paulo: Editora Unifesp, 2019. 180 p. - (Sendas \& Veredas)}

Renan Cortez*

Definições precisas, linguagem sóbria e econômica, argumentos claros e apresentação detalhada de resultados. Em Idealismo e Realismo na Filosofia de Nietzsche, Itaparica desenvolveu uma abordagem à maneira analítica de enfrentar problemas filosóficos. O que caracteriza essa tradição de interpretação não é o consenso a respeito de teses, mas o modo como os problemas são interpelados. $\mathrm{Na}$ verdade, os intérpretes "analíticos" discordam, e muito: um dos efeitos positivos da agonística constantemente estimulada é o

\footnotetext{
* Universidade Federal de Minas Gerais, Belo Horizonte, Minas Gerais, Brasil. ORCID https://orcid.org/0000-0003-3170-1793

Correio eletrônico: renancortez22@gmail.com
} 
Cortez, R.

refinamento de argumentos diferentes, muitas vezes conflitantes. $\mathrm{O}$ livro que veio a público ano passado (2019) é uma versão abreviada da tese que Itaparica defendeu em 2003, no programa de PósGraduação da Universidade de São Paulo. Neste intervalo de tempo, a abordagem "anglo-saxã" ganhou espaço no Brasil: revistas científicas publicaram edições com contribuições de pesquisadores nacionais e internacionais ${ }^{1}$. Formou-se, portanto, um contexto intelectual convidativo: não resta dúvida que a obra foi publicada em momento propício.

Itaparica propôs uma solução original para um problema clássico da literatura secundária: afinal, a vontade de potência é uma interpretação humana, demasiado humana, ou uma descrição objetiva da realidade? O autor é a favor de uma erradicação da disjuntiva: nem idealista e nem realista, Nietzsche superou essa dicotomia quando formulou a sua madura ontologia dos processos. O que significa tal superação? A resposta foi oferecida no terceiro e último capítulo do livro. No lugar certo, pois não haveria solução sem um prévio esclarecimento dos significados de idealismo e de realismo e sem uma reconstrução do desenvolvimento das reflexões de Nietzsche sobre a relação entre fenômeno (aparência) e coisa em si (essência). Estes são os temas dos capítulos 1 e 2, respectivamente. Disposta em ordem linear, a obra em nada se assemelha a um labirinto.

Com efeito, é fato que Nietzsche aborda "idealismo" e "realismo" em suas obras - afinal, o problema kantiano da "coisa em si" é um tema que aparece em todos os momentos da sua produção filosófica ${ }^{2}$. Contudo, não é com um vocabulário fixo que Nietzsche aborda os temas mais frequentes do debate sobre realismo e idealismo: o intérprete que opta pela fidelidade ao vocabulário do autor pode não cumprir a função que lhe cabe, ou seja, a de esclarecer, pois as ambiguidades

1 Ver: Cadernos Nietzsche, n. 29, 2011 e Kriterion, Vol.54, n.128, 2013.

2 Anos após a produção da tese, Itaparica escreveu um artigo específico sobre o problema da coisa em si. Ver: As objeções de Nietzsche ao conceito de coisa em si. In: Kriterion, vol.54, no.128, Belo Horizonte Dec. 2013.

212 | Cad. Nietzsche, Guarulhos/Porto Seguro, v.41, n.2, p. 211-221, maio/agosto, 2020. 
e as flutuações estão na fonte primária. Ciente desta dificuldade, o intérprete talvez prefira explorar o debate contemporâneo sobre antirrealismo - saída que está, no entanto, associada ao perigo do anacronismo. Pode ainda recorrer a um diálogo com a tradição filosófica, mas os termos têm suas histórias e as histórias os seus pesos e, nesse caso, há o perigo de tornar Nietzsche refém daqueles que o precederam.

O autor apresenta o debate contemporâneo, reconstrói temas da história da filosofia e aborda a obra de Nietzsche em sua complexidade. Sabe dos riscos e com prudência evita os equívocos. Logo na introdução, avisa ao leitor que recorrerá às obras de John Searle, Nelson Goodman e Hilary Putnam apenas com o objetivo de esclarecer conceitualmente os termos que serão usados na tese (Itaparica, 2019, p.28). A aproximação exclusivamente metodológica afasta a ameaça do anacronismo e possibilita precisão conceitual, afinal, os autores mencionados são cuidadosos com os conceitos. $\mathrm{O}$ resultado dessa abordagem foi apresentado no início do primeiro capítulo: realismo e idealismo são diferentes teses a respeito da independência dos entes em relação às representações humanas. Realistas alegam que há um modo de existência das coisas que é logicamente independente das representações humanas (p.31), e idealistas defendem, por sua vez, a tese segundo a qual podemos conhecer apenas objetos que dependem da mente (asserções, crenças, pensamentos etc.), mas nunca o mundo em si mesmo. Com tais definições em mãos, Itaparica inicia o segundo momento do primeiro capítulo: uma reconstrução do debate sobre idealismo e realismo na história da filosofia moderna. Após reconstruir, o autor apresenta algumas ilustrativas comparações das posições de Nietzsche com as de Descartes, Berkeley, Kant, Schopenhauer e Albert Lange. Nietzsche não se torna refém daqueles que o precederam, pois com essas comparações Itaparica demarca o lugar singular do filósofo alemão na história da filosofia moderna. 
Cortez, R.

No segundo capítulo, o autor desenvolve uma abordagem detalhada da fonte primária. Não reproduz as ambiguidades, pois conquistou o necessário esclarecimento conceitual. Sua abordagem é genética: existem três principais fases do pensamento de Nietzsche e certas diferenças sutis em cada uma. Os momentos seguem o esquema da divisão tradicional: juventude, período intermediário e maturidade. $\mathrm{Na}$ juventude, Nietzsche confia na distinção entre essência e aparência e defende a possibilidade de um acesso místico à primeira. A música ditirâmbica conduz o indivíduo a uma ruptura com o princípio da individuação e possibilita a experiência de uma reconciliação com a coisa em si - o Uno primordial. Há, então, para o jovem Nietzsche, um modo de existência das coisas que é logicamente independente da mente, ou seja, independente do mundo fenomênico (apolíneo). O acesso a esse "em si", contudo, não é feito pela linguagem, pois ela se refere apenas a representações: o conhecimento discursivo pressupõe o princípio da razão suficiente, ou seja, não ultrapassa os limites do "mundo como representação". De acordo com Itaparica, esta tese foi apresentada em $O$ nascimento da tragédia e reafirmada em Sobre a verdade e a mentira em sentido extramoral. Nesta obra não publicada, Nietzsche defendeu o caráter tropológico da linguagem e apresentou suas instigantes identificações dos juízos com as metonímias, das generalizações com as sinédoques e do tempo, espaço e causalidade com as metáforas. A verdade é definida como um "batalhão móvel de metáforas": dos seus estudos sobre retórica clássica, Nietzsche extraiu uma criativa teoria da percepção e da linguagem. Assim, confirma-se a continuidade: a linguagem discursiva não possibilita um acesso ao "em si" e Nietzsche não se opõe em momento algum à metafísica do artista (p. 73). No entanto, nesse texto a posição de Nietzsche tornou-se mais nuançada, pois a metafísica do artista convive com um "inesperado" ceticismo (pp.73-4). O texto pressupõe uma filosofia da representação e, por conseguinte, a admissão da existência de uma coisa em si. Nietzsche 
também afirma, contudo, que não é possível definir positivamente e nem negativamente como se dá a relação entre a essência (a coisa em si) e a representação. A constatação do "ceticismo inesperado" é um momento importante no percurso argumentativo de Itaparica, pois anuncia o período intermediário.

De acordo com o autor, na obra que inaugura o período intermediário, Nietzsche almeja "questionar qualquer forma de em si" (p. 75). Itaparica destaca que essa crítica ao "em si” está diretamente relacionada com o programa do filosofar histórico. Nietzsche basicamente argumenta que a faculdade do entendimento, responsável pela produção do "mundo como representação", surgiu e desenvolveu-se no interior da história natural. Nietzsche se mostra cético a respeito da possibilidade de ultrapassarmos os limites do mundo como representação: nem a intuição e nem a linguagem conceitual nos ajudam. Podemos concluir que sua posição está mais próxima do idealismo? Não é tão simples; Nietzsche não afirma apenas que o intelecto produz o mundo como representação: ele associa diretamente o "mundo como representação" a um erro. $\mathrm{Na}$ formulação precisa de Itaparica:

(...) Há uma grande diferença entre afirmar que não podemos garantir que nossas representações correspondam a um mundo exterior, cuja existência, por isso mesmo, pode ser dubitável, e afirmar que o mundo que não é representação difere essencialmente delas (...). (p.78).

O compromisso com a filosofia do devir é o elemento que explica essa diferença. De acordo com Itaparica, em Humano, demasiado humano há uma oposição entre dois mundos. De um lado está o mundo da representação: o intelecto produz a inteligibilidade deste mundo a partir de uma lei originária, isto é, baseado no "princípio do incondicionado" ou simplesmente "lei da substância". Esse é o conceito mais primitivo e dele se derivam as sensações de tempo e de espaço, a nossa concepção de movimento, a nossa percepção 
Cortez, R.

quantitativa dos fenômenos e outros elementos importantes. O mundo efetivo, por sua vez, é o "devir incessante": a representação está associada, desse modo, ao erro, porque não corresponde à essência dinâmica do real. Itaparica reconhece que nessa obra o devir adquire o estatuto de algo que existe independente da mente humana (p.79). Surge, então, um problema: Nietzsche não se propôs a criticar toda e qualquer forma de "em si"? É verdade que a oposição contida no livro não é entre a coisa em si (o real) e o mundo fenomênico (aparente), pois o próprio filósofo identifica a coisa em si com a substância, ou seja, com o erro. Entretanto, o sentido da oposição epistemológica permanece intacto: o "em si" é uma realidade processual inacessível e o "mundo fenomênico" está estruturado de acordo com a categoria da substância. A despeito de importantes diferenças, se compreendida em sentido exclusivamente epistemológico, a gramática que sustenta essa oposição ainda é kantiana.

O problema recebeu uma nova abordagem em A gaia ciência: Itaparica avalia que Nietzsche deu passos importantes na direção de sua teoria madura, mas permaneceu refém do vocabulário e das concepções idealistas. Lembra o autor que Nietzsche menciona, no famoso aforismo 54, a necessidade de superar a oposição entre "essência e aparência"; contudo, apesar de reconhecer a inexistência de um "em si", o filósofo afirma que a própria realidade, a única que existe, é aparência (p.83). Nietzsche caminha na direção da abolição da oposição, mas não exclui o correlato da coisa em si: o fenômeno. O resultado é uma preponderância do idealismo: a redução do mundo à aparência, ao mesmo tempo em que elimina o dualismo tende a um idealismo (p. 85).

Itaparica reconhece, portanto, que a posição apresentada por Nietzsche no período intermediário não é satisfatória (p.94). O terceiro período é diferente, pois Nietzsche estende sua crítica à própria noção de aparência. $\mathrm{O}$ suporte dessa interpretação é o conhecido aforismo sobre a história de um erro: a abolição do mundo 
verdadeiro também resulta na abolição do mundo aparente. Clark, uma referência importante para o autor, apresentou uma tese genética que, ao menos na estrutura, é semelhante a esta. Para a autora, o período intermediário é insuficiente, pois permanecem resíduos idealistas: Nietzsche poderia ter abolido a oposição entre fenômeno e coisa em si, pois havia concluído que a coisa em si é um objeto contraditório, mas não assumiu a posição correta porque seu pensamento ainda estava sob a influência de teorias da percepção langeanas e schopenhauerianas (Clark, 1990, pp. 95-103,). A conclusão correta estava próxima, afinal, se não faz sentido se referir a um “em si”, então, nenhuma referência metafísica extrínseca à perspectiva humana deveria ser assumida como parâmetro para a validação dos nossos juízos. Entretanto, no período intermediário, o filósofo permaneceu comprometido com o ficcionalismo, pois adotou a tese segundo a qual a nossa linguagem conceitual falsifica uma camada primária das nossas representações, a saber, o caos das sensações. Somente no período de maturidade Nietzsche extraiu as consequências de sua crítica ao conceito de coisa em si: se não há uma referência extra-perspectivística, disto se segue que podemos nos reconciliar com uma noção não metafísica de verdade. Uma teoria poderá ser considerada verdadeira se apresentar uma descrição bem-sucedida da experiência e for capaz de satisfazer os nossos interesses cognitivos.

A interpretação de Clark não concede espaço algum para a ontologia da vontade de potência, pois a autora aceita a orientação metodológica que prioriza as obras publicadas, o que reduz as ocorrências da ontologia. Nesse ponto, a interpretação de Itaparica seguiu um caminho diferente, visto que para o autor a vontade de potência é o aspecto central da teoria madura de Nietzsche. Os dois caminhos produzem retratos diferentes do filósofo analisado. Para Clark, Nietzsche se reconciliou com o realismo de senso comum e rejeitou a validade de teorias apriorísticas. Por sua vez, Itaparica avalia 
Cortez, R.

que a solução para o problema epistemológico é uma especulação ontológica sobre os processos e os eventos ${ }^{3}$.

Esse é o assunto do último capítulo do livro. No início, há uma exposição de como essa proposta supera o idealismo de matriz kantiana, principalmente o schopenhaueriano, e de que modo se diferencia do materialismo atomista. Basicamente, o idealismo schopenhaueriano tem dois problemas principais: (1) a pressuposição da doutrina dos dois mundos, e (2) "a definição do mundo verdadeiro por meio de conceitos vazios, alcançados através da generalização e da suposição de unidades" (p. 119). Nietzsche supera essa perspectiva quando afirma que não existe a vontade: não há, portanto, "o mundo verdadeiro", a "unidade primordial" ou o "ser". Na efetividade, existem múltiplas vontades de potência em relação de tensão. Assim, nos passos de Müller-Lauter, Itaparica afirma que Nietzsche se diferencia de Schopenhauer porque, em sua ontologia, estão presentes a multiplicidade e o antagonismo. Quanto ao segundo inimigo, o autor lembra que Nietzsche reconhece alguns dos méritos do materialismo: a economia do método, a previsibilidade e o rigor da explicação. Isto não o impede, contudo, de ressaltar os limites filosóficos dessa leitura. São eles: a subordinação das explicações mecanicistas às crenças que adquirimos por intermédio do tato e da visão, a sua incapacidade de abarcar os aspectos qualitativos da existência e, principalmente, o problema que já havia incomodado Newton: a dificuldade de compatibilizar a teoria corpuscular da matéria com a noção de ação à distância (pp. 121-24). Nietzsche estava ciente do problema e seguiu, em linhas gerais, a solução oferecida por Boscovich: a substituição do modelo corpuscular pela noção de pontos de força não extensos. Acrescentou, ainda, à força uma qualidade interna - a vontade de potência. Baseado nesse modelo, o filósofo formulou a sua ontologia dos quanta de poder (p. 134).

30 autor aborda essa e outras diferenças em relação à leitura de Clark na introdução do livro (pp.21-5) 
Na introdução, Itaparica admite que George Stack foi o autor que mais se aproximou de sua abordagem do problema (p.16). No entanto, destacou a diferença: em razão de sua interpretação langeana, Stack não reconhece que o conceito de vontade de potência foi elaborado com o objetivo de resolver problemas teóricos. Na visão de Stack, a vontade de potência é uma poesia conceitual que atende a fins eminentemente práticos: ela é apenas uma interpretação, uma explícita "antropomorfização" da física dinâmica de Boscovich (Stack, 2005, p.59). Assim, Stack mantém o idealismo, pois a vontade de potência é concebida como uma interpretação criativa da totalidade da existência, ou seja, é "mind-dependent". Itaparica, por sua vez, defende que essa ontologia pode satisfazer os nossos interesses cognitivos, afinal, com a elaboração do conceito de vontade de potência, Nietzsche superou duas correntes tradicionais da história da filosofia.

A exposição do significado dessa superação é complexa, pois envolve a abordagem de múltiplos temas: a relação entre a vontade de potência e as ontologias processuais, a diferença entre os argumentos circulares apresentados na Crítica da Razão Pura e a circularidade da vontade de potência e o próprio significado desta intricada proposta ontológica. Itaparica desenvolveu cada um desses temas com argúcia e rigor. Eis a suma: Nietzsche concorda com o idealista quando afirma que não faz sentido conceber uma "coisa" sem relação com uma percepção; mas supera o idealismo, porque não concebe a perspectiva humana como o único centro de produção de inteligibilidade do mundo: o fato de sabermos que o "mundo" aparece para o homem de acordo com um determinado recorte interpretativo não significa que haja apenas esse recorte. Pelo contrário, Nietzsche afirma que existem infinitas perspectivas e, por conseguinte, infinitos mundos possíveis. Assim, a perspectiva "humana" é uma entre outras e ela mesma não é nenhuma unidade. Expressamos uma unidade porque a linguagem exige uma abreviação 
Cortez, R.

para fins de comunicação, mas na realidade o que chamamos de perspectiva humana é uma multiplicidade dinâmica de vontades de potências. Do mesmo modo, ao "transcender" a perspectiva humana, Nietzsche não se torna um realista, pois continua comprometido com a ideia de que a inteligibilidade do real depende de interpretações. Não há, portanto, um "modo de ser das coisas" que é logicamente independente das interpretações.

Itaparica resumiu o significado dessa superação na seguinte formulação:

O que chamamos de aparência, assim, é produto não de uma mente inextensa, mas fruto da própria perspectividade que constitui também o inorgânico. Desse modo, a realidade do mundo se constitui justamente desses processos perspectivísticos que criam aparências. A capacidade de aparecer é aquilo que encerra a realidade do mundo como vontade de potência. Conceitos classicamente opostos, aparência e realidade estão unidas em um mesmo processo (p.159).

O livro termina com uma exposição da relação entre a vontade de potência e a ontologia dos processos: diferentemente de Kant, Nietzsche não concebe a mudança como uma transformação nos acidentes de uma substância, nem tampouco defende que "coisa" seja o produto de processos. Para o filósofo, "a substância" e os conceitos a ela associados são ilusões grosseiras (p.154). Entretanto, dificilmente podemos comunicar essa ontologia do processo sem recorrer às simplificações da linguagem (p. 155). Desse modo, usamos a expressão "a atividade da vontade de potência" como se o segundo termo designasse um sujeito autoconstituído e apartado de sua ação e da sua relação com outros processos, mas tal sujeito não existe: o que existe é a ação, a própria atividade. Os processos são ações sem sujeito, assim como relâmpagos (p. 156).

Na conclusão do livro, Itaparica apresenta o percurso e os resultados de sua pesquisa com a objetividade natural do seu estilo. Além disso, o autor explora com mais detalhes as relações entre 
Nietzsche, Hilary Putnam e Nelson Goodman. No capítulo 1, a abordagem foi exclusivamente metodológica, mas na conclusão as comparações filosóficas apareceram. A obra é marcante pela pluralidade de abordagens: diálogo com autores contemporâneos, reconstrução da história da filosofia, debate com os comentadores e tese genética. Faltava um interlocutor: o pesquisador brasileiro. Para a alegria dos pares, a tese tornou-se pública um ano após seu aniversário de debutante.

\section{Review}

\section{Beyond Realism and Idealism}

\section{Referências}

CLARK, M. Nietzsche on truth and philosophy. Cambridge: Cambridge University Press, 1990.

ITAPARICA, A. Idealismo e Realismo na Filosofia de Nietzsche. São Paulo: Editora Unifesp, 2019. 180 p. - (Sendas \& Veredas) - As objeções de Nietzsche ao conceito de coisa em si. In: Kriterion vol.54 no.128 Belo Horizonte Dec. 2013.

STACK, George. Nietzsche's anthropic circle: Man, Science and Myth. New York: University of Rochester press, 2005.

Recebida: 15/03/2020

Aceita:15/04/2020 